\title{
AUDIT SISTEM INFORMASI PENGAWASAN DAN PEMANTAUAN PERMINTAAN LAYANAN DAN INSIDEN MENGGUNAKAN COBIT 5 PADA PT TELKOM REGIONAL WHOLESALE SERVICE 3 JAWA BARAT
}

\author{
Tri Ramdhany ${ }^{1}$, Marsya Diyni Nur'adila² \\ Program Studi Sistem Informasi Politeknik LPKIA ${ }^{1}$,Program Studi Sistem Informasi STMIK LPKIA ${ }^{2}$ \\ Jln. Soekarno Hatta No. 456 Bandung 40255, Telp. +62 22 75642823, Fax. +62 227564282 \\ Email : trilpkia@gmail.com ${ }^{1}$, marsya.nuradila@gmail.com ${ }^{2}$
}

PT Telkom memiliki sistem informasi yang berperan sebagai manajemen surveillance dan monitoring (pengawasan dan pemantauan) dengan memiliki fungsi inventory (kebutuhan data alat produksi), fulfillment (pemenuhan kebutuhan pelanggan) dan assurance (jaminan layanan yang diberikan). Sehingga dapat mempermudah peningkatan pelayanan kepada pelanggan untuk mengelola pemasangan baru dan memantau serta menindaklanjuti apabila terjadi gangguan setiap waktu. Sistem informasi pegawasan dan pemantauan permintaan layanan $\&$ insiden juga sebagai pendukung terlaksananya proses bisnis untuk mencapai tujuan perusahaan. Oleh karena itu dilakukannya audit untuk mengetahui sejauh mana kesesuaian Sistem informasi pegawasan dan pemantauan permintaan layanan \& insiden dengan tujuan perusahaan, dengan menggunakan framework COBIT 5 pada domain DSS (Deliver, Service and Support). Berdasarkan hasil pemetaan menggunakan COBIT 5 yang didapatkan dari strategi perusahaan dipetakan kedalam enterprise goals dan IT-related goals sehingga didapat proses yang akan dinilai yaitu DSS02 (Manage Service Request and Incident).

Hasil pencapaian yang didapatkan untuk proses DSS02 pada level 1 dan 2 sudah tercapai karena hasil pencapaian melebihi $85 \%$ yang berarti ada bukti pada proses yang dinilai dan pencapaian penuh, sehingga pencapaian akhir untuk proses DSS02 berada pada level 3 yaitu Established Process bahwa proses yang dikelola telah diimplementasikan menggunakan proses definisi yang mana mampu mencapai hasil prosesnya. Dari hasil pencapaian kondisi saat ini dan yang diharapkan terdapat gap sebesar 0,42 untuk mencapai level 4, sehingga dibuatkan rekomendasi agar dapat mencapai targetnya dan mengimplementasikan salah satu dari rekomendasi yang telah didapatkan.

Kata Kunci : Audit, pelayanan pelanggan, COBIT 5

$P T$ Telkom has an information system that acts as a surveillance and monitoring management by having an inventory function (production equipment data requirements), fulfillment of customer needs and assurance (guaranteed service provided). So that it can facilitate the improvement of service to customers to manage new installations, monitor and follow up if there is a disruption every time. Monitoring information system and monitoring of service requests \& incidents as well as supporting the implementation of business processes are used to achieve company goals. Therefore, an audit is carried out to determine the suitability of the monitoring information system and monitoring of service requests \& incidents with the company's objectives, using the COBIT 5 framework in the DSS (Deliver, Service and Support) domain. Based on the results of mapping using COBIT 5 obtained from the company's strategy mapped into enterprise goals and IT-related goals so that the process to be assessed is DSSO2 (Manage Service Request and Incident). Results obtained for the DSSO2 process at levels 1 and 2 have been achieved because the achievement results exceed $85 \%$ which means that there is evidence of the process being assessed and full achievement, so the final achievement for the DSSO2 process is at level 3 namely the Established Process that the managed process has been implemented using a process definition which is able to achieve the results of the process. From the results, it can be concluded that the current conditions and expected there is a gap of 0.42 to reach level 4 , so recommendations are made in order to achieve its targets and implement one of the recommendations that have been obtained.

Keywords: Audit, customer service, COBIT 5

\section{Pendahuluan}

PT Telkom Regional Wholesale Service 3 Jabar bergerak pada bidang penyedia infrastruktur telekomunikasi, fasilitas dan layanan kepada pelantara untuk dijual ke pengguna akhir. 
JURNAL NUANSA INFORMATIKA

Volume 14 Nomor 1, Januari 2020

Perusahaan ini juga memiliki sistem informasi yang berperan sebagai surveillance dan monitoring atau pengawasan dan pemantauan untuk mengelola permintaan layanan dan insiden dari pelanggan. Dalam proses bisnis yang sedang berjalan sistem informasi ini menjadi salah satu penunjang agar proses bisnis selanjutnya dapat dicapai sesuai dengan tujuan perusahaan. Apabila salah satu proses terhambat maka proses bisnis selanjutnya tidak berjalan dan akan mempengaruhi terhadap tujuan perusahaan serta kinerja karyawan dalam meningkatkan pelayanan pada pelanggan.

Oleh Karena itu, agar sistem informasi yang telah diterapkan dapat berjalan sesuai dengan proses bisnis dan tujuan perusahaan maka diperlukan pengelolaan untuk menjaga layanan kepada pelanggan agar dapat diselesaikan secara cepat dan tepat sasaran, sehingga diperlukan adanya audit sistem informasi pengawasan dan pemantauan permintaan layanan dan insiden menggunakan kerangka kerja COBIT 5.

Berdasarkan latar belakang tersebut tujuan dari penelitian ini adalah :

1. Untuk mengetahui hasil pencapaian capability level pada sistem informasi pengawasan dan pemantauan permintaan layanan \& insiden di Telkom RWS 3 JABAR.

2. Untuk mengetahui temuan-temuan hasil audit sistem informasi dengan menggunakan COBIT 5 berdasarkan domain DSS (Deliver, Service and Support) dan Proses DSS02 (Manage Service Request and Incident).

3. Untuk memberikan rekomendasirekomendasi yang menjadi masukkan untuk perusahaan yang berkaitan dengan sistem informasi pengawasan dan pemantauan permintaan layanan dan insiden di Telkom RWS 3 JABAR.
p-ISSN : 1858-3911, e-ISSN : 2614-5405

https://journal.uniku.ac.id/index.php/ilkom

\subsection{Metodologi Penelitian}

Metode penelitian yang digunakan adalah kerangka kerja COBIT 5 dengan domain DSS (Deliver, Service and Support) dan proses DSS02 Manage Service Request and Incident. COBIT (Control Objectives for Information and Related Technology) merupakan kerangka panduan tata kelola TI dan atau bisa juga disebut sebagai toolset pendukung yang bisa digunakan untuk menjembatani gap antara kebutuhan dan bagaimana teknis pelaksanaan pemenuhan kebutuhan tersebut dalam suatu organisasi. [1]

Tahapan Goals Cascade COBIT 5 merupakan tahapan untuk menentukan proses yang akan di assessment pada penelitian ini menggunakan tahapan goals cascade pada COBIT, yaitu dengan mendefinisikan kebutuhan stakeholder, lalu dipetakan pada Enterprise Goals dan IT-Related Goals, selanjutnya menentukan proses yang akan dinilai dengan memetakan Process Control.

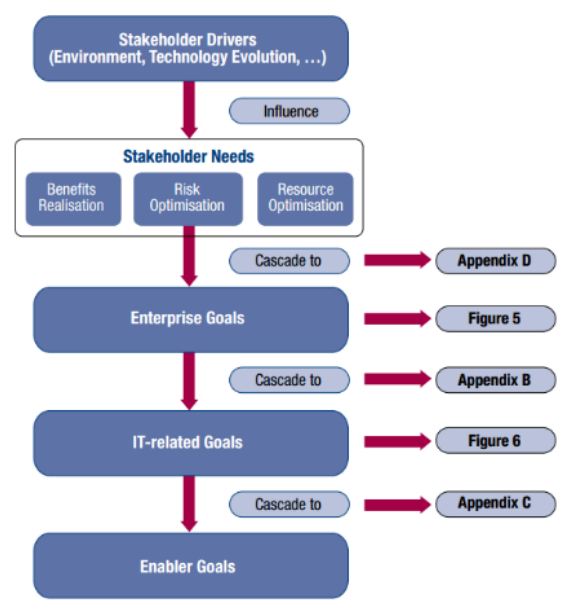

Gambar 1. 1 Goals Cascade

a. Stakeholder Needs

Kebutuhan stakeholder ditransformasikan menjadi strategi yang dapat ditindak lanjuti oleh perusahaan

b. Pemetaan Enterprise Goals

Pemetaan strategi perusahaan dengan Enterprise Goals pada COBIT 5 
JURNAL NUANSA INFORMATIKA

Volume 14 Nomor 1, Januari 2020

ditentukan melalui dimensi-dimensi pada Balanced Scorecard (BSC). Pemetaan ini merupakan tahap awal dalam melakukan analisa dan menentukan tujuan umum perusahaan.

c. Pemetaan IT-Related Goals

Setelah dilakukannya pemetaan strategi perusahaan terhadap enterprise goals, ditemukannya hasil pemetaan lalu dilakukan pemetaan dari hasil yang terpilih pada Enterprise Goals terhadap IT-Related Goals. Pemetaan ini disesuaikan dengan COBIT 5 appendix B yang terlampir pada lampiran. Pemetaan ini juga untuk mencapai tujuan perusahaan, didukung dengan adanya tujuan terkait IT yang dijabarkan pada dimensi-dimensi dari IT Balanced Scorecard (IT BSC).

d. Pemetaan Processes Control

Setelah dilakukan pemetaan enterprise goals terhadap IT-Related Goals dihasilkan IT-RG yang terpilih berdasarkan $\mathrm{P}$ (primary) yang kemudian dipetakan ke Enabler goals untuk mengetahui domain dan proses mana yang akan di assessment. Pemetaan tersebut berdasarkan dari COBIT 5 pada appendix $\mathrm{C}$ yang terdapat pada lampiran.

\section{Dasar Teori}

\subsection{Audit Sistem Informasi}

Audit Sistem Informasi dimaksudkan untuk mengevaluasi tingkat kesesuaian antara sistem informasi dengan prosedur bisnis (business processes) perusahaan (atau kebutuhan pengguna, user needs), untuk mengetahui apakah suatu sistem informasi telah didesain dan diimplementasikan secara efektif, efisien dan ekonomis, memiliki mekanisme pengamanan aset, serta menjamin integritas data yang memadai. [2]

Audit sistem informasi adalah proses pengumpulan data dan pengevaluasian bukti-bukti untuk menentukan apakah suatu sistem aplikasi komputerisasi telah menetapkan dan menerapkan sistem pengendalian internal yang memadai, semua aktiva dilindungi dengan baik atau tidak disalahgunakan penyelenggaraan sistem informasi berbasis komputer. [2]

\subsection{Tujuan Audit}

Tujuan audit sistem informasi menurut Gondodiyoro yaitu : [2]

1. Pengamann Aset

Aset informasi suatu perusahaan seperti perangkat keras (hardware), perangkat lunak (software), sumber daya manusia, file/ data dan fasilitas lain harus dijaga dengan sistem pengendalian intern yang baik agar tidak terjadi penyalahgunaan aset perusahaan.

2. Efektifitas Sistem

Efektifitas sistem informasi perusahaan memiliki peranan penting dalam proses pengambilan keputusan. Suatu sistem informasi dapat dikatakan efektif apabila sistem informasi tersebut sudah dirancang dengan benar, telah sesuai dengan kebutuhan user. Informasi yang dibutuhkan oleh para manajer dapat dipenuhi dengan baik.

3. Efisiensi Sistem

Efisiensi menjadi sangat penting ketika sumber daya kapasitasnya terbatas. Jika cara kerja dari sistem aplikasi komputer menurun maka pihak manajemen harus megevaluasi apakah efisiensi sistem masih memadai atau harus menambah sumber daya, karena suatu sistem dapat dikatakan efisien jika sistem informasi dapat memenuhi kebutuhan user dengan sumber daya informasi yang minimal.

4. Ketersediaan

Berhubungan dengan ketersediaan dukungan/ layanan teknologi informasi (TI). TI hendaknya dapat mendukung secara kontinyu terhadap 
JURNAL NUANSA INFORMATIKA

Volume 14 Nomor 1, Januari 2020

proses bisnis (kegiatan perusahaan). Makin sering gangguan maka berarti tingkat keterseiaan sistem rendah.

5. Kerahasiaan

Fokusnya ialah pada proteksi terhadap informasi da supaya terlindungi dari akses dari pihakpihak yang tidak berwenang.

6. Kehandalan

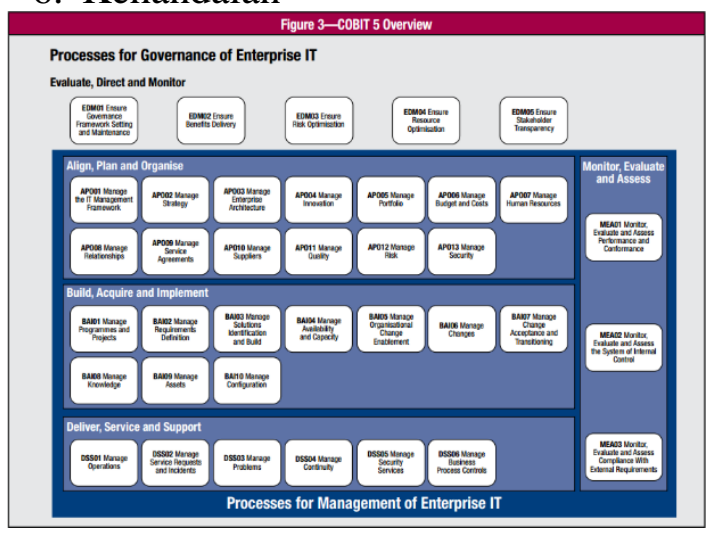

Berhubungan dengan kesesuaian dan keakuratan bagi manajemen dalam pengelolaan organisasi, pelaporan dan pertanggungjawaban.

7. Menjaga integritas data

Integritas data adalah salah satu konsep dasar sistem informasi. Data memiliki atribut-atribut seperti: kelengkapan, kebenaran, dan keakuratan.

\subsection{Pengawasan (Surveillance)}

Pengawasan ialah keseluruhan upaya pengamatan pelaksanaan kegitan operasional guna menjamin bahwa berbagai kegiatan tersebut sesuai dengan rencana yang telah ditetapkan sebelumnya. [3]

\subsection{Pemantauan (Monitoring)}

Monitoring adalah proses pengumpulan dan analisis informasi berdasarkan indikator yang ditetapkan secara sistematis dan kontinu tentang kegiatan/ program sehingga dapat dilakukan tindakan koreksi untuk penyempurnaan program/ kegiatan itu sendiri. [4]
p-ISSN : 1858-3911, e-ISSN : 2614-5405

https://journal.uniku.ac.id/index.php/ilkom

\subsection{Pelayanan Pelanggan}

Pada dasarnya pengertian pelayanan pelanggan adalah suatu aktivitas yang dilakukan untuk meningkatkan kepuasan pelanggan. Pelayanan pelanggan dapat merupakan suatu alat komunikasi dimana atas dasar ini, perusahaan-perusahaan dapat mengetahui kegiatan pelanggan serta melayani keluhan-keluhannya sehingga pada akhirnya dapat memberikan kepuasan kepada pelanggan tersebut.

Pelayanan Konsumen meliputi berbagai aktivitas diseluruh area bisnis yang berusaha mengkombinasikan mulai dari pemesanan, memproses, sehingga pemberian hasil jasa melalui komunikasi untuk mempererat kerja sama dengan konsumen. [5]

\subsection{COBIT 5}

Secara sederhana, COBIT 5 membantu enterprise membangun nilai yang optimal dari TI dengan mengelola keseimbangan antara realisasi manfaat dan optimasi Level resiko dan penggunaan sumberdaya.

COBIT 5 memungkinkan informasi dan teknologi yang terkait untuk dikelola secara holistik bagi keseluruhan enterprise, mencakup area bisnis dan fungsional secara keseluruhan, dengan

Gambar 2. 1 Domain dan Proses COBIT 5

mempertimbangkan manfaat TI bagi stakeholders internal dan eksternal. COBIT 5 mempunyai dua area yaitu governance dan management yang terdiri dari 37 proses. [6]

\subsection{Prinsip COBIT 5}

Menurut ISACA, COBIT 5 memiliki 5 (Lima) prinsip dasar yaitu : [6]

1. Memenuhi kebutuhan stakeholder 
JURNAL NUANSA INFORMATIKA

Volume 14 Nomor 1, Januari 2020

2. Melingkupi tata kelola dan proses kerja End-to-End Enterprise

3. Mengaplikasikan sebuah kerangkakerja yang terintegrasi

4. Pendekatan keseluruhan untuk kemampuan tata kelola dan manajemen/ pengaturan

5. Pemisahan antara tata-kelola dengan manajemen/pengaturan

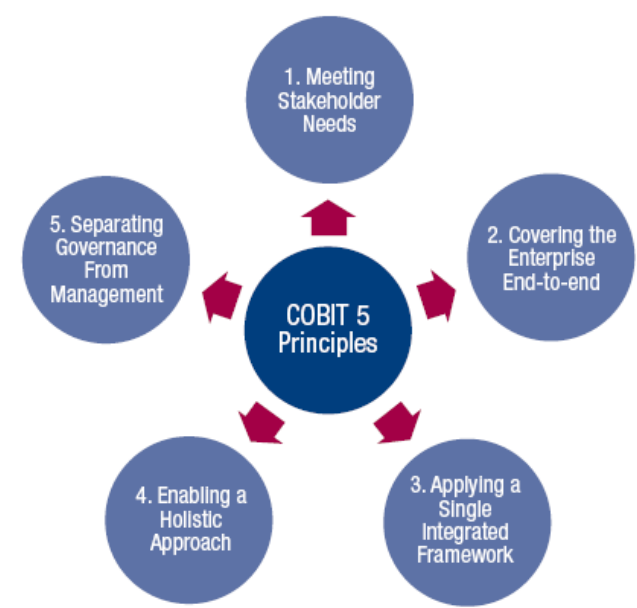

Gambar 2. 2 Prinsip COBIT 5

\subsection{Process Assessment Model}

Model penilaian pada COBIT 5 berbeda dengan penilaian pada COBIT 4.1 Produk dari COBIT 5 termasuk dalam process capability model yang proses penilaiannya menggunakan ISO/IEC 15504. Process Capability Model merupakan pedoman untuk mengukur peformansi dari setiap proses dan peningkatan pada area yang telah diinginkan dengan memberikan skor pada masing-masing proses. Terdapat 6 level kapabilitas proses yang bisa dicapai oleh proses tatakelola yaitu level 0 sampai 5 (performed process, managed process, established process, predictable process, optimizing process). [7]

\subsection{Assessment Indicator}

Penilaian Process capability model menggunakan 2 tipe indikator, yaitu : [7]
p-ISSN : 1858-3911, e-ISSN : 2614-5405

https://journal.uniku.ac.id/index.php/ilkom

1. Process Capability Indicators, yang digunakan pada kapabilitas tingkat (Level) 2-5, antara lain Generic Practice (GPs) dan Generic Work Product (GWPs).

2. Process Performance Indicators, yang digunakan hanya pada tingkat (Level) 1, antara lain Base Practice dan Work Products.

\subsection{Skala Penilaian}

Setiap proses yang dinilai akan menghasilkan 4 level rating point, yaitu :

[7]

a. Not achieved, apabila hasil penilaian antara $0 \%-15 \%$

b. Partally achieved, apabila hasil penilaian $>15 \%-50 \%$

c. Largely achieved, apabila hasil penilaian $>50 \%-85 \%$

d. Fully achieved, apabila hasil penilaian $>85 \%-100 \%$

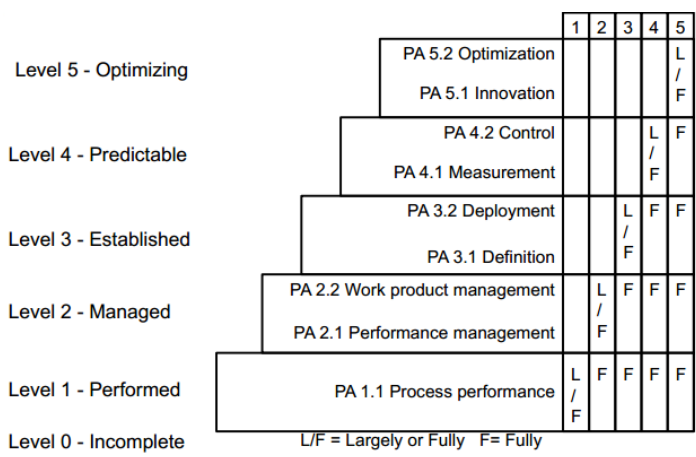

Gambar 2. 3 Penilaian Proses atribut

\section{Analisis dan Pembahasan}

\subsection{Kondisi Saat ini}

Pada pembahasan analisis kondisi organisasi saat ini menjelaskan bagaimana keadaan kondisi layanan TI saat ini yang ada pada Telkom RWS 3 JABAR, dengan menggunakan bantuan kerangka kerja COBIT 5 kuesioner berdasarkan domain proses DSS02. Dari hasil penilaian kuesioner didapatkan dari hasil perhitungan pencapaian capability yang dapat dilihat rincian perhitungannya pada lampiran perhitungan capability. Berikut 
JURNAL NUANSA INFORMATIKA

Volume 14 Nomor 1, Januari 2020

adalah Rekapitulasi nilai capability sebagai berikut :

Tabel 3. 1 Rekapitulasi Nilai Capability

\begin{tabular}{|l|l|l|l|}
\hline Proses & $\begin{array}{c}\text { Process } \\
\text { Attibut } \\
\boldsymbol{e}(\boldsymbol{P A})\end{array}$ & $\begin{array}{c}\text { Hasil } \\
\text { pencapaia } \\
\text { n }\end{array}$ & $\begin{array}{c}\text { Leve } \\
\text { l }\end{array}$ \\
\hline \multirow{4}{*}{$\begin{array}{c}\text { DSS0 } \\
2\end{array}$} & PA 1.1 & $93 \%$ & 1 \\
\cline { 2 - 4 } & PA 2.1 & $92 \%$ & 2 \\
\cline { 2 - 4 } & PA 2.2 & $100 \%$ & 2 \\
\cline { 2 - 4 } & PA 3.1 & $90 \%$ & 3 \\
\cline { 2 - 4 } & PA 3.2 & $83 \%$ & 3 \\
\hline
\end{tabular}

Berdasarkan tabel diatas, maka didapatkan bahwa kondisi saat ini pada sistem informasi pengawasan dan pemantauan permintaan layanan \& insiden terdapat pada level 3, karena hasil terakhir yang didapatkan adalah $83 \%$ pada PA 3.2 sehingga tidak dapat lanjut ke level selanjutnya karena syarat yang telah ditetapkan oleh COBIT 5 yaitu syarat apabila naik level selanjutnya harus memiliki skala penilaian fully achieved (hasil pencapaian $>85 \%-100 \%$ ).

\subsection{Kondisi yang diharapkan}

Kondisi yang diharapkan oleh perusahaan didapatkan dari hasil analisis berdasarkan kuesioner dan wawancara dengan pihak terkait yang terdapat pada pembahasan kondisi saat ini, terdapat aktivitas yang semula tidak tercapai kemudian ingin dicapai atau menjelaskan proses yang akan diperbaiki atau yang diharapkan untuk kedepannya dan untuk memastikan bahwa sistem yang sudah berjalan dapat selaras dengan tujuan organisasi. Rincian Analisis kondisi yang diharapkan perusahaan terdapat pada Tabel III.15.

\subsection{Gap}

Untuk memperoleh hasil Level Gap yaitu didapatkan dari hasil pencapaian antara kondisi saat ini dengan kondisi yang diharapkan yang telah dibahas di pembahasan sebelumnya pada tabel analisis kondisi saat ini dan tabel analisis kondisi yang diharapkan. Kondisi existing didapat dari data yang diperoleh melalui kuesioner dan wawancara, kemudian Level target diperoleh dari wawancara dengan pihak terkait berdasarkan dari hasil kuesioner.

Tabel 3. 2 Analisis GAP

\begin{tabular}{|l|l|l|l|}
\hline $\begin{array}{l}\text { Process } \\
\text { Atribute }\end{array}$ & $\begin{array}{l}\text { Level } \\
\text { Existin } \\
\text { g } \\
\text { (Kondi } \\
\text { si saat } \\
\text { ini) }\end{array}$ & $\begin{array}{l}\text { Level } \\
\text { Target } \\
\text { (Kondisi } \\
\text { yang } \\
\text { diharapkan } \\
\text { ) }\end{array}$ & $\begin{array}{l}\text { Ga } \\
p\end{array}$ \\
\hline PA 1.1 & 0,93 & 1 & $\begin{array}{l}0,0 \\
7\end{array}$ \\
\hline PA 2.1 & 0,92 & 1 & $\begin{array}{l}0,0 \\
8\end{array}$ \\
\hline PA 3.1 & 0,90 & 1 & $\begin{array}{l}0,1 \\
0\end{array}$ \\
\hline PA 3.2 & 0,83 & 1 & $\begin{array}{l}0,1 \\
7\end{array}$ \\
\hline $\begin{array}{l}\text { Total } \\
\text { Pencapaia } \\
\text { n DSS02 }\end{array}$ & $\mathbf{3 , 5 8}$ & $\mathbf{4}$ & $\begin{array}{l}\mathbf{0 , 4} \\
\mathbf{2}\end{array}$ \\
\hline
\end{tabular}

Total pencapaian DSS02 dihasilkan dari nilai rata-rata per-level sehingga menghasilkan Level Existing 3,58 yang berarti kondisi saat ini terdapat pada level 3. Untuk level target juga dari nilai ratarata per-level yang menghasilkan nilai 4 berarti kondisi yang diharapkan perusahaan berada pada level 4 . Berdasarkan hasil tersebut terdapat gap antara kondisi saat ini dan yang kondisi yang diharapkan oleh perusahaan sebesar 0,42 .

\section{Solusi / Rekomendasi}

Berdasarkan dari hasil analisis kesenjangan pada tabel III.16 Analisis Gap dan uraian pada halaman III-73, dibuatlah model solusi berdasarkan gap yang dijabarkan sesuai dengan tahapan pada framework COBIT 5 yang telah dilakukan. 
JURNAL NUANSA INFORMATIKA

Volume 14 Nomor 1, Januari 2020

Untuk mengatasi gap antara kondisi saat ini dan kondisi yang diharapkan oleh perusahaan dibuatlah solusi/ rekomendasi dengan rincian untuk atribut dan aktivitas dapat dilihat secara rinci pada tabel III.17 Tabel Perancangan model solusi.

Dari Tabel tersebut dapat disimpulkan bahwa terdapat 6 aktivitas yang menjadi gap antara kondisi saat ini dan yang diharapkan, dari keenam aktivitas tersebut sudah dijabarkan mengenai gap permasalahan dan dibuatkannya solusi atau rekomendasi dari hasil analisis yang sudah dilakukan.

\section{Kesimpulan dan Saran 5.1 Kesimpulan}

Penelitian telah dilakukan pada objek penelitian sistem informasi pengawasan dan pemantauan permintaan layanan \& insiden di PT Telkom Regional Wholesale 3 JABAR dengan menggunakan bantuan kerangka kerja COBIT 5 pada domain DSS (Delivery, Service and Support) dapat disimpulkan sebagai berikut :

1. Pencapaian mengenai sistem informasi pengawasan dan pemantauan permintaan layanan \& insiden pada kondisi saat ini berada pada level 3 (Established Process) bahwa proses yang dikelola telah diimplementasikan menggunakan proses definisi yang mana mampu mencapai hasil prosesnya. Hasil pencapaian di level 3 didapat dari perhitungan per level, dengan rincian rincian per proses atribut sebagai berikut : PA 1.1 mencapai sebesar 0,93 atau $93 \%$, PA 2.2 mencapai sebesar 0,92 atau 92\%, PA 3.1 mencapai sebesar 0,90 atau $90 \%$ dan PA 3.2 mencapai sebesar 0,83 atau $83 \%$, yang berarti tidak dapat melanjutkan ke level berikutnya karena kurang dari $85 \%$. Sedangkan dari perhitungan, kondisi yang diharapkan oleh perusahaan berada pada level 4.

2. Dari hasil pencapaian kondisi saat ini dan kondisi yang diharapkan oleh perusahaan terdapat gap sebesar 0,42 untuk mencapai level 4, oleh karena itu dilakukan identifikasi mengenai kesenjangan dan dibuatkan rekomendasi yang sesuai dengan aktivitas pada DSS02 COBIT 5.

3. Dari beberapa rekomendasi yang telah diuraikan hanya satu yang diimplementasikan sebagai usulan untuk perusahaan berdasarkan aktivitas pada DSS02 COBIT 5, yaitu membuat database untuk pendistribusian atau pengiriman laporan hasil dari rekapan sistem yang berjalan dengan aplikasi TeNOSS, yang dapat diakses oleh ADM Support dan pihak-pihak yang berkepentingan lainnya.

\subsection{Saran}

Berikut adalah saran yang dapat disampaikan untuk penelitian selanjutnya adalah :

a. Saran untuk Peneliti selanjutnya :

Melakukan analisis dengan menggunakan metode COBIT 5 dengan domain Deliver Service and Support dengan proses selain DSS02 agar dapat melengkapi dari hasil penelitian yang sudah dilakukan.

b. Saran untuk Perusahaan :

Melakukan dan memperbaiki aktivitas yang belum terlaksanakan untuk mencapai kondisi yang diharapkan seperti memetakan setiap bagian pekerja kedalam RACI dan dikomunikasikan. 
JURNAL NUANSA INFORMATIKA

Volume 14 Nomor 1, Januari 2020
p-ISSN : 1858-3911, e-ISSN : 2614-5405

https://journal.uniku.ac.id/index.php/ilkom

\section{Daftar Pustaka}

Buku :

[1] ISACA, COBIT 5 Introduction, 2012.

[2] S. Gondodiyoto, Audit Sistem Informasi + Pendekatan CobIT, Jakarta: Mitra Wacana Media, 2010.

[3] S. P. Siagian, Manajemen Stratejik, Jakarta: PT Bumi Aksara, 2012.

[5] Rambat Lupiyoadi, A. Hamdani, Manajemen Pemasaran Jasa (Edisi 3), Jakarta: Salemba Empat, 2013.

[6] ISACA, Enabling Processes, ISACA, 2012.

[7] ISACA, Process Assessment Model (PAM): Using COBIT 5, ISACA, 2013.

[8] Telkom, "Laporan Tahunan Telkom," Telkom Indonesia, Jakarta, 2015.

[9] ISACA, A Bussines Framework for the Governance and Management of Enterprise IT, United State of America, 2012.

Jurnal :

[4] G. T. Mardiani, "Sistem Monitoring Data Aset dan Inventaris PT Telkom Cianjur Berbasis Web," Jurnal Ilmiah Komputer dan Informatika (KOMPUTA) Vol. 2, No. 1, Maret, ISSN : 2089-9033, 2013. 